\title{
Predicting adherence to acupuncture appointments for low back pain: a prospective observational study
}

\author{
Felicity L. Bishop ${ }^{1 *}$, Lucy Yardley ${ }^{1}$, Cyrus Cooper ${ }^{2}$, Paul Little ${ }^{3}$ and George Lewith ${ }^{3}$
}

\begin{abstract}
Background: Acupuncture is a popular form of complementary and alternative medicine (CAM), but it is not clear why patients do (or do not) follow acupuncturists' treatment recommendations. This study aimed to investigate theoretically-derived predictors of adherence to acupuncture.

Methods: In a prospective study, adults receiving acupuncture for low back pain completed validated questionnaires at baseline, 2 weeks, 3 months, and 6 months. Patients and acupuncturists reported attendance. Logistic regression tested whether illness perceptions, treatment beliefs, and treatment appraisals measured at 2 weeks predicted attendance at all recommended acupuncture appointments.

Results: Three hundred twenty-four people participated (aged 18-89 years, $M=55.9$, SD =14.4; 70\% female). 165 (51\%) attended all recommended acupuncture appointments. Adherence was predicted by appraising acupuncture as credible, appraising the acupuncturist positively, appraising practicalities of treatment positively, and holding pro-acupuncture treatment beliefs. A multivariable logistic regression model including demographic, clinical, and psychological predictors, fit the data well $\left(x^{2}(21)=52.723, p<.001\right)$, explained $20 \%$ of the variance, and correctly classified $65.4 \%$ of participants as adherent/non-adherent.

Conclusions: The results partially support the dynamic extended common-sense model for CAM use. As hypothesised, attending all recommended acupuncture appointments was predicted by illness perceptions, treatment beliefs, and treatment appraisals. However, experiencing early changes in symptoms did not predict attendance. Acupuncturists could make small changes to consultations and service organisation to encourage attendance at recommended appointments and thus potentially improve patient outcomes.
\end{abstract}

Keywords: Acupuncture, Adherence, Back pain, Health knowledge, Attitudes, Practice, Illness perceptions, Treatment beliefs

\section{Background}

The inclusion of acupuncture in clinical practice guidelines for chronic back pain encourages increased integration of acupuncture into mainstream healthcare systems $[1,2]$. As more acupuncture is funded by and accessed through public health care systems, acupuncture research needs to expand beyond questions of efficacy and incorporate a focus on questions related to health services and healthcare delivery. Poor attendance at appointments

\footnotetext{
* Correspondence: F.L.Bishop@soton.ac.uk

'Psychology, Faculty of Social and Human Sciences, University of

Southampton, Building 44 Highfield Campus, Southampton SO17 1BJ, UK

Full list of author information is available at the end of the article
}

contributes to wasted resources throughout health care $[3,4]$ and could reduce the effectiveness of acupuncture. This study therefore investigated the predictors of full attendance at recommended acupuncture treatments in a cohort of patients with low back pain (LBP), a common reason for using acupuncture $[5,6]$.

Attendance for a course of treatments can be conceptualised as a form of adherence - the extent to which patients follow specific recommendations that have been agreed with a health care practitioner [7]. Research on acupuncture has rarely focused explicitly on adherence. However, good adherence predicts better outcomes in other therapies, including among patients taking placebos 
[8]. This suggests that good adherence might also predict better outcomes in acupuncture. One research letter reported that only 13 of 32 participants in a small clinical study completed all ten acupuncture treatments, suggesting that attendance can be poor [9]. Major trials of individualised acupuncture for back pain have reported the number of appointments attended but not compared this to recommendations, making it difficult to ascertain adherence [10-12]. Qualitative studies suggest that after initiating treatment, patients particularly value aspects of the relationship with the acupuncturist (e.g. individualised holistic caring consultations; egalitarian or collaborative relationships; length of time with the acupuncturist; seeing the same acupuncturist) and immediate and longer-term health benefits (e.g. the treatment itself being relaxing and enjoyable; improvements in symptoms, wellbeing, and function; gaining new insights into one's health and/or treatment) [13-18]. In one study patients valued more mundane practicalities of treatment (e.g. clinics running to time) [19]. Patients' reasons for stopping acupuncture can include financial considerations (although some patients make sacrifices elsewhere to enable on-going access) and perceived lack of effect $[13,18]$. In the NHS in particular, patients are dissatisfied with inflexible appointment times and fixed (short) courses of treatment $[13,16,20]$ which could lead to poor attendance.

Research on adherence to other forms of complementary and alternative medicine (CAM) suggests that patients evaluate CAMs against multiple criteria including: congruence with health-related beliefs; impact on and insight into symptoms, wellbeing, and energy levels; the quality of the therapeutic relationship; and practicalities such as financial cost [21-25]. Quantitative studies suggest that continued or committed use of CAMs might be higher in people with greater on-going medical need [26] health worries [27] and pro-CAM attitudes such as holistic models of health [28]. In surveys, respondents describe stopping CAM because it is too expensive, has not had the desired effects, or has been completely effective [29, 30]. Different personality traits predict adherence to CAM in different studies, including absorption [31], agreeableness [32], and low neuroticism [33]. Dissatisfaction with biomedicine can trigger initial CAM use but appears to be less relevant to decisions about ongoing CAM use [21, 26, 28].

An extended Common-Sense Model (CSM) provides a comprehensive and testable framework within which to study adherence to treatment [34-36]. According to this model, patients hold abstract beliefs about illness ('illness perceptions') and treatments ('treatment beliefs') which inform decisions to initiate treatment. Studies confirm that illness perceptions and treatment beliefs are indeed associated with CAM use [37-39]. Having initiated treatment, patients then continue or discontinue it based on a combination of abstract beliefs and concrete experiences such as improvements in symptoms or side-effects [40-42]. The CSM further specifies that relationships between concrete experiences and abstract beliefs are bidirectional [43]. One implication of this is that experiencing early improvements during treatment should not only predict adherence but should also strengthen the illness perceptions and treatment beliefs that originally led to treatment uptake. Adherence research within this framework has focused mainly on illness perceptions and treatment beliefs in long-term medication regimes for chronic illness and has shown that illness perceptions are only weakly associated with adherence [44] while treatment beliefs are stronger, more proximal determinants of adherence [34, 45]. Patients with chronic illness are more adherent to prescribed medication when beliefs about personal need for the medicine outweigh any concerns about it [46].

We have previously adapted the extended CSM to study adherence to CAM by suggesting that patients appraise four particular aspects of CAM therapies: the therapy itself, the therapist, practicalities (e.g. convenience, cost), and symptom improvements early in treatment [28]. Qualitative data suggest relationships between these factors; for example, lack of improvement early in treatment might not deter patients if they are encouraged to continue treatment by their therapist [21, 42]. Appraisals of the therapy itself may be less important for adherence than appraisals of other aspects: in a longitudinal study adherence to CAM was predicted by positive appraisals of the therapist and practicalities but not the therapy [28] More trusting and patient-centered therapeutic relationships have also been shown to increase adherence to biomedical treatments [47-49]. The dynamic extended CSM for CAM is shown in Fig. 1.

This study used the dynamic extended CSM for CAM to investigate adherence to acupuncture. The aim was to identify the predictors of full attendance at recommended acupuncture treatments in a cohort of patients with LBP. Specifically, we hypothesised that full attendance would be predicted by appraising the acupuncturist positively, appraising practicalities of treatment positively, experiencing early improvements in symptoms, holding pro-acupuncture treatment beliefs, and having positive perceptions of one's LBP. We also hypothesised that experiencing early improvements in symptoms and appraising the acupuncturist positively would predict pro-acupuncture treatment beliefs and positive perceptions of LBP.

\section{Methods}

\section{Design}

The data for this analysis are drawn from a larger prospective observational cohort of patients with LBP receiving acupuncture [50]. Participants completed paper-based 


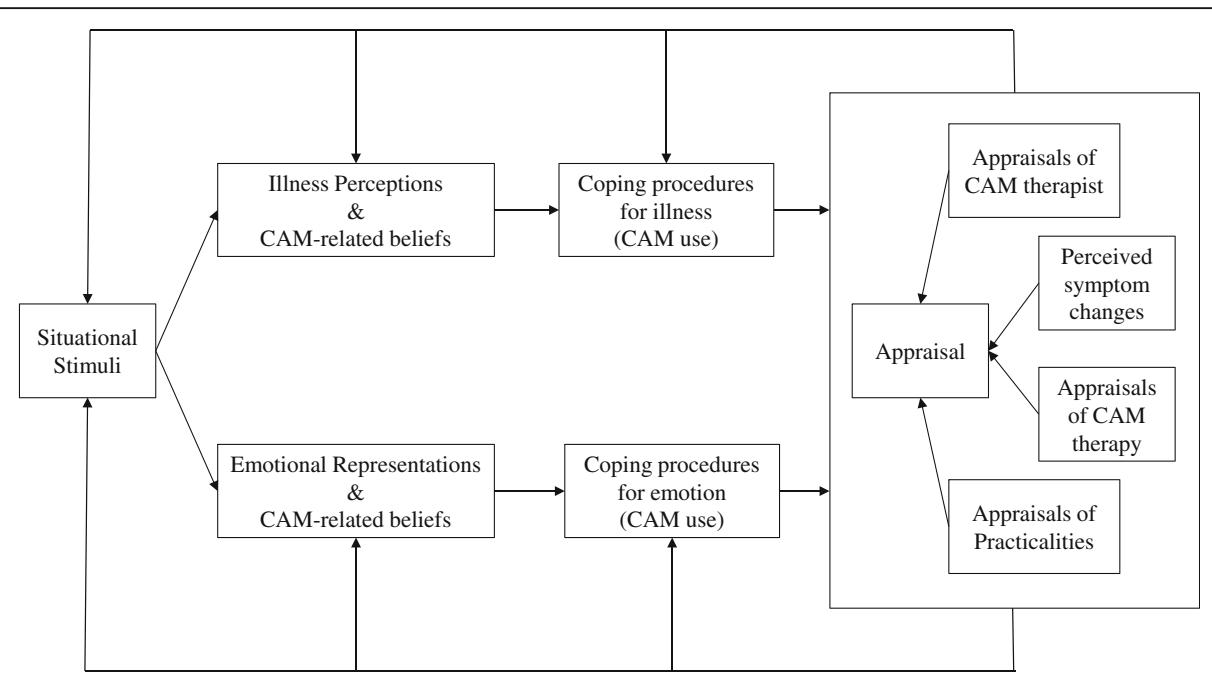

Fig. 1 A dynamic extended common-sense model for CAM use. Adapted from [28] and originally adapted from the dynamic model of treatment perceptions [42] and the extended common sense model of self-regulation [34, 36]

questionnaire measures of health and psychological variables four times - before starting treatment, 2 weeks, 3 months (when most courses of acupuncture for LBP have been completed), and 6 months later. Hypothesised predictors of adherence derived from the extended common-sense model were illness perceptions, treatment beliefs, and appraisals. This analysis used the 2-week measures of predictors unless otherwise specified (as pretreatment beliefs should predict treatment initiation but not necessarily maintenance). The primary outcome was adherence at 3 months. The protocol was approved by Southampton and South West Hampshire Research Ethics Committee (A) (08/H0502/92) and data collection occurred between November 2008 and October 2010.

\section{Measures}

All questionnaires were chosen for their theoretical relevance, psychometric properties, and brevity.

\section{Predictors}

Illness perceptions were measured using the validated and reliable 8-item Brief Illness Perceptions Questionnaire [51] worded specifically to assess perceptions of LBP. Eight single items assess perceptions of LBP as having severe consequences (consequences), lasting a long time (timeline), being controllable by the patient (personal control), being treatable (treatment control), causing many severe symptoms (identity), being worrying (concerns), being understandable (coherence), and having emotional effects (emotional). An open-ended question asks participants to identify three causes of their own LBP. All named causes were reviewed and inductively categorised, creating five separate binary variables. Fear avoidance beliefs and catastrophising can be conceptualised as illness perceptions specifically relevant to pain and were also included. Fear avoidance beliefs about physical activity and work were measured using the validated and reliable four and sevenitem subscales from the Fear Avoidance Beliefs Questionnaire [52] (Cronbach's $\alpha$ in this sample $=0.78$ and 0.90 respectively). Catastrophising was measured using the validated and reliable 6-item subscale from the Coping Strategies Questionnaire [53] $(\alpha=0.90)$.

Four dimensions of treatment beliefs were measured using the validated and reliable Complementary and Alternative Medicine Beliefs Inventory (CAMBI) [54] and Credibility Expectancy Questionnaire (CEQ) [55]. On the CAMBI, six items assessed holistic health beliefs $(\alpha=0.67)$, six items assessed beliefs that treatments should be 'natural' or non-toxic $(\alpha=0.83)$, and five items assessed belief that patients should actively participate in treatment $(\alpha=0.63)$. On the CEQ, three items assessed expectations that acupuncture is an effective treatment for LBP $(\alpha=0.94)$.

Four aspects of appraisals were measured. Appraisals of the acupuncturist were measured using the validated and reliable 10-item perceptions of therapist subscale from the Treatment Appraisal Questionnaire (TAQ) [28] $(\alpha=0.91)$. Appraisals of the credibility of acupuncture for LBP were measured using the three item credibility subscale from the CEQ $(\alpha=0.88)$. Appraisals of practicalities were measured using five single-items from the TAQ which were highly skewed and so negatively phrased items were reverse-scored and then all items dichotomised into "strongly agree" vs all other responses. Thus participants were classified according to whether they appraised their acupuncture as: value for money, not difficult to travel to, convenient appointments, not too much effort to attend, and not too expensive. Three dimensions of appraisals of early symptom changes were 
measured: back-related disability, using the 24-item Roland Morris Disability Questionnaire [56]; pain, using an 11-item numerical rating scale [57]; and wellbeing, using the single-item (100 mm visual analogue scale) Arizona Integrative Outcomes Scale [58]. Early symptom changes were assessed by calculating change scores on these three measures of health status, subtracting pre-treatment scores from 2-week scores. Continuous measures of health changes were used in the analyses of relationships among appraisals, illness perceptions and treatment beliefs, because linear relationships were hypothesised among these variables. For the analyses of predictors of adherence, participants were classified into five groups on each of the change variables (moderate improvement, small improvement, no change, small deterioration, moderate deterioration - see Table 1 for cut-offs). This classification facilitated investigation of non-linear relationships between health changes and adherence, e.g. any deterioration might discourage attendance, small improvements might encourage attendance, while large improvements might lead to early discontinuation.

\section{Outcome}

The duration of acupuncture treatment is often evaluated on an on-going basis and negotiated between patient and acupuncturist, resulting in individualised recommendations for the number of treatments (although this is less common in the NHS than the private sector [59]). Adherence was therefore operationalised as the extent to which patients attended all appointments as recommended by/agreed with their acupuncturist. Participants reported this on a 7-point likert scale. Acupuncturists reported, for each patient, the number of appointments recommended and the number attended. Acupuncturists' recommendations were made based on usual clinical practice. A dichotomous measure of adherence (complete attendance vs incomplete attendance) was computed based on a combination of acupuncturists' and participants' reports - for a patient to be categorised as adherent both the patient and their acupuncturist had to report complete attendance.

\section{Procedure and participants}

Eighty three acupuncturists ( 24 male, 59 female) were recruited from CAM clinics, general practice, pain clinics, and physiotherapy departments across Great Britain and Northern Ireland. They distributed baseline questionnaire packs (including information leaflets and consent forms) to consecutive eligible patients (aged over 18, scoring at least four on the Roland Morris Disability Questionnaire [56], no malignant pain). Patients returned questionnaires and consent forms to the researchers in Freepost envelopes. Subsequent questionnaires were mailed directly to patients. Gift vouchers and personalised and repeated follow-ups were used to enhance recruitment and retention [60,61]. Four hundred and eighty five patients were recruited, of whom 324 provided attendance data and were included in this analysis.

\section{Statistical analyses}

Missing values analysis in SPSS showed the proportion of missing data was low and Missing at Random, thus missing values were imputed using EM [62]. Analysis in MLWin confirmed that there was no significant effect on adherence of clustering of patients within clinics and so no adjustments for clustering were required.

To test hypotheses concerning predictors of adherence, SPSS was used to compute a series of univariable logistic regressions. Significant predictors (at $p<.10$ ) were entered into multivariable hierarchical logistic regression to identify independent predictors of adherence and to assess whether psychological variables predict adherence after controlling for demographic and clinical characteristics. Clinical and demographic variables were entered in Block 1, psychological variables were entered in Block 2. Variables were forced to enter the model within each block. The appropriateness of the data for logistic regression was tested. The Box-Tidwell procedure confirmed the data satisfied the assumption of linearity of the logit [63]. A linear regression was run and collinearity diagnostics examined; this confirmed there was no multicollinearity: all tolerance values $>0.1$, all $\operatorname{VIF}<10$, no evidence of dependence in the variance

Table 1 Cut points for health change categories

\begin{tabular}{llll}
\hline Category & Change scores in category & & \\
\cline { 2 - 4 } & Disability (RMDQ) & Pain (NRS) & Wellbeing (AIOS) \\
\hline Small deterioration & 1 to 4 & 1 & -7 to 2 \\
Moderate deterioration & $>=4$ & $>=2$ & $<=-7$ \\
No change & 0 & 0 & $2-11$ \\
Small improvement & -1 to -4 & -1 & 11 to 24 \\
Moderate improvement & $<=-4$ & $<=-2$ & $>=24$
\end{tabular}

Notes. ${ }^{a}$ 4-point change on Roland Morris Disability Questionnaire is clinically/statistically meaningful [75]. ${ }^{\mathrm{b}}$ Patients view 2 point reduction on Numerical Rating Scale as moderately meaningful [76]. ${ }^{\complement}$ No guidance available for Arizona Integrative Outcome Scale so quintile split used 
of the regression co-efficients [64]. To test hypothesises concerning relationships among treatment appraisals, treatment beliefs and illness perceptions, partial correlations were conducted between continuous measures of these variables (controlling for baseline treatment beliefs and illness perceptions).

\section{Results}

\section{Demographic and clinical characteristics and adherence}

Table 2 summarises participants' characteristics and presents the results of univariable logistic regressions to predict adherence. A slight majority of participants $(51 \%, n=165)$ attended all their recommended appointments. Participants were aged between 18 and 89 years old $(M=55.9, S D=14.4)$. The majority were female, had chronic LBP, had not had acupuncture before, were receiving acupuncture in the public sector and were having other treatment(s) alongside acupuncture. Patients who were more likely to attend all their acupuncture appointments were older, had previous experience of acupuncture, were receiving additional treatments, were receiving acupuncture in the NHS, and were receiving acupuncture in a physiotherapy, GP, or pain clinic. Characteristics that were not significantly associated with attendance were: gender, duration of LBP, having a comorbid condition, and economic factors (see Table 2).

\section{Psychological variables and adherence}

Table 3 summarises scores on the psychological variables and presents the results of univariable logistic regressions to predict adherence. One illness perception dimension predicted adherence: the odds of attending all appointments decreased with perceptions that one's LBP causes many severe symptoms (illness identity). Two dimensions of treatment beliefs predicted adherence: the odds of attending all appointments increased with higher expectations of effectiveness and stronger preferences for participating in treatment. Five dimensions of appraisals predicted adherence: the odds of attending all appointments increased with more positive appraisals of the acupuncturist, appraisals of acupuncture as credible, and appraising appointments as convenient, not too much effort to attend, and affordable. Changes in disability, wellbeing, or pain scores in the first 2 weeks of treatment did not predict adherence.

Table 4 presents the results of the hierarchical multivariable logistic regressions to predict adherence. Demographic and clinical characteristics were entered in Block 1 and this model was a good fit to the data $\left(\chi^{2}(11)=\right.$ $25.899, \mathrm{p}=.007)$, but explained only approximately $10 \%$ of the variance in attendance (Nagelkerke's $R^{2}=0.102$ ), and resulted in $62.7 \%$ of participants being correctly classified as adherent/non-adherent. Adding psychological variables in Block 2 significantly improved model fit $\left(\chi^{2}(10)=26.824, \mathrm{p}=.003\right)$. The final model including demographic, clinical, and psychological variables was a good fit to the data $\left(\chi^{2}(21)=52.723, p<.001\right)$, explained approximately $20 \%$ of the variance in attendance (Nagelkerke's $R^{2}=0.200$ ), and resulted in $65.4 \%$ of participants being correctly classified as adherent/non-adherent. Two variables remained as a significant independent predictor of adherence: the odds of attending all appointments were 1.23 times lower for every 1-unit increase in illness identity (perceptions that LBP causes many severe symptoms) and 2.09 times higher for participants who strongly disagreed that "seeing my therapist can be too much effort".

\section{Appraisals, illness perceptions, and treatment beliefs}

Table 5 summarises the partial correlations between appraisals and illness perceptions and treatment beliefs. After controlling for baseline beliefs, appraising acupuncture as credible, appraising the acupuncturist positively, and experiencing early health improvements were all associated with positive treatment beliefs and illness perceptions 2 weeks into treatment. In particular, positive appraisals were associated with higher expectations of acupuncture's effectiveness, perceiving higher levels of personal and treatment-related control over LBP, and perceiving one has a good understanding of LBP. Out of the four dimensions of appraisals, experiencing early health improvements were the most strongly and consistently associated with treatment beliefs and illness perceptions 2 weeks into treatment. Appraisals of practicalities of treatment were only weakly associated with illness perceptions and treatment beliefs. Positive appraisals were not associated with more general CAM-related beliefs.

\section{Discussion}

Data from a longitudinal prospective cohort study were used to investigate the predictors of complete attendance for a course of acupuncture for LBP. As hypothesised, adherence to appointments was predicted by appraising acupuncture as credible, appraising the acupuncturist positively, appraising practicalities of treatment positively, and holding pro-acupuncture treatment beliefs. Contrary to predictions, experiencing early changes in symptoms did not predict attendance, which makes it likely that our findings are not conflated by treatment effects. Experiencing early symptom improvements and appraising acupuncture and the acupuncturist positively were all associated with higher expectations of acupuncture's effectiveness and perceptions of LBP as more controllable and comprehensible.

In the univariable models, patients who had higher odds of attending all of their acupuncture appointments were older, had previous experience of acupuncture, were receiving additional treatments, were receiving 
Table 2 Descriptive statistics and simple logistic regression analyses of demographic and clinical characteristics predicting attendance $(n=324)$

\begin{tabular}{|c|c|c|c|c|c|c|}
\hline \multirow[t]{3}{*}{ Characteristic } & \multicolumn{2}{|c|}{ Descriptive statistics } & \multicolumn{4}{|c|}{ Regression results } \\
\hline & \multirow[t]{2}{*}{$f$} & \multirow[t]{2}{*}{$\%$} & \multirow{2}{*}{$\begin{array}{l}\text { Odds } \\
\text { Ratio }\end{array}$} & \multicolumn{2}{|c|}{ 95\% Confidence Interval } & \multirow[t]{2}{*}{$p$} \\
\hline & & & & Lower & Upper & \\
\hline \multicolumn{7}{|l|}{ Personal characteristics } \\
\hline Age & - & - & $1.02^{*}$ & 1.00 & 1.04 & .012 \\
\hline \multicolumn{7}{|l|}{ Gender } \\
\hline Female & 228 & 70.4 & 1.51 & 0.93 & 2.43 & .094 \\
\hline Education & & & & & & .743 \\
\hline Left school aged $<16$ years ${ }^{a}$ & 38 & 11.7 & & & & \\
\hline Educated to 16 & 136 & 42 & 1.04 & 0.51 & 2.14 & .909 \\
\hline Educated to 18 & 80 & 24.7 & 0.90 & 0.42 & 1.95 & .789 \\
\hline Post-school education & 70 & 21.6 & 0.76 & 0.34 & 1.67 & .492 \\
\hline \multicolumn{7}{|l|}{ Economic factors } \\
\hline Compensation claim pending & 30 & 9.3 & 0.96 & 0.45 & 2.04 & .915 \\
\hline Receiving back-related benefits & 58 & 17.9 & 1.34 & 0.76 & 2.38 & .316 \\
\hline Employment & & & & & & .259 \\
\hline Employed at usual work ${ }^{a}$ & 109 & 33.6 & & & & \\
\hline On restricted duties & 72 & 22.2 & 1.12 & 0.61 & 2.03 & .718 \\
\hline Unpaid work (house work, student, retired) & 143 & 44.1 & 1.50 & 0.91 & 2.47 & .114 \\
\hline \multicolumn{7}{|l|}{ Clinical factors } \\
\hline Prior acupuncture & 133 & 41 & $1.61^{*}$ & 1.03 & 2.52 & .037 \\
\hline Comorbidity & 156 & 48.1 & 1.32 & 0.85 & 2.04 & .217 \\
\hline Co-treatment & 256 & 79 & $1.78^{*}$ & 1.03 & 3.06 & .039 \\
\hline LBP duration & & & & & & .429 \\
\hline Acute $(<6 \text { weeks })^{a}$ & 41 & 12.7 & & & & \\
\hline Persistent (6-52 weeks) & 103 & 31.8 & 0.72 & 0.35 & 1.50 & .385 \\
\hline Chronic (>52 weeks) & 180 & 55.6 & 0.99 & 0.50 & 1.95 & .970 \\
\hline \multicolumn{7}{|l|}{ Clinic characteristics } \\
\hline \multicolumn{7}{|l|}{ Sector } \\
\hline Private & 111 & 34.3 & $0.50^{*}$ & 0.31 & 0.80 & .004 \\
\hline Acupuncture style & & & & & & .059 \\
\hline Unclear $^{a}$ & 60 & 18.5 & & & & \\
\hline Western & 164 & 50.6 & 0.97 & 0.54 & 1.76 & .922 \\
\hline Traditional or TCM & 85 & 26.2 & 0.52 & 0.27 & 1.01 & .055 \\
\hline Mixed & 15 & 4.6 & 1.64 & 0.50 & 5.37 & .416 \\
\hline Clinic type & & & & & & .070 \\
\hline CAM or acupuncture/TCM ${ }^{a}$ & 96 & 29.6 & & & & \\
\hline Physiotherapy & 83 & 25.6 & $1.90^{*}$ & 1.05 & 3.44 & .035 \\
\hline Pain clinic & 95 & 29.3 & $1.85^{*}$ & 1.04 & 3.28 & .037 \\
\hline GP & 50 & 15.4 & $2.11^{*}$ & 1.05 & 4.22 & .035 \\
\hline
\end{tabular}

Notes. ${ }^{*} p<.05 .{ }^{* *} p<.01 .{ }^{a}$ Reference category

acupuncture in the NHS, and were receiving acupuncture in physiotherapy, GP, or pain clinics (compared to acupuncture or CAM clinics). This suggests that previous acupuncture users are more committed to treatment than patients new to acupuncture, probably because the former are returning for a treatment they previously found effective. Receiving additional treatments might indicate worse overall health which could increase 
Table 3 Descriptive statistics and univariable logistic regression analyses of adherence on psychological variables $(n=324)$

\begin{tabular}{|c|c|c|c|c|c|c|c|c|}
\hline & \multicolumn{4}{|c|}{ Descriptive statistics } & \multicolumn{4}{|c|}{ Regression results } \\
\hline & \multirow[t]{2}{*}{$f$} & \multirow[t]{2}{*}{$\%$} & \multirow[t]{2}{*}{$M$} & \multirow[t]{2}{*}{ SD } & \multirow{2}{*}{$\begin{array}{l}\text { Odds } \\
\text { Ratio }\end{array}$} & \multicolumn{2}{|c|}{ 95\% C.I. } & \multirow[t]{2}{*}{$p$} \\
\hline & & & & & & Lower & Upper & \\
\hline \multicolumn{9}{|l|}{ Illness perceptions } \\
\hline LBP as threatening & - & - & 47.63 & 10.73 & 0.99 & 0.97 & 1.01 & .173 \\
\hline Consequences & & & 6.82 & 2.11 & 1.00 & 0.91 & 1.11 & .935 \\
\hline Timeline & & & 7.78 & 2.18 & 0.97 & 0.88 & 1.07 & .514 \\
\hline Personal control & & & 4.54 & 2.33 & 1.03 & 0.94 & 1.13 & .580 \\
\hline Treatment control & & & 6.62 & 2.18 & 1.10 & 1.00 & 1.22 & .058 \\
\hline Identity & & & 6.95 & 1.86 & 0.89 & 0.79 & 1.00 & .050 \\
\hline Concerns & & & 7.86 & 1.96 & 0.99 & 0.88 & 1.10 & .792 \\
\hline Comprehensible & & & 6.83 & 2.57 & 1.08 & 0.99 & 1.18 & .085 \\
\hline Emotional & & & 6.21 & 2.46 & 1.01 & 0.93 & 1.11 & .800 \\
\hline Caused by activities of daily living & 120 & 37.0 & - & - & 0.89 & 0.57 & 1.40 & .627 \\
\hline Caused by work & 140 & 43.2 & - & - & 0.85 & 0.55 & 1.32 & .460 \\
\hline Caused by accident/injury & 123 & 38.0 & - & - & 0.83 & 0.53 & 1.29 & .405 \\
\hline Caused by aging/genes & 92 & 28.4 & - & - & 1.07 & 0.66 & 1.74 & .777 \\
\hline Caused by disease & 102 & 31.5 & - & - & 1.06 & 0.66 & 1.70 & .801 \\
\hline Fear avoidance- physical activity & & & 14.54 & 5.52 & 0.98 & 0.94 & 1.02 & .301 \\
\hline Fear avoidance- work & & & 15.17 & 13.11 & 0.97 & 0.98 & 1.01 & .599 \\
\hline Catastrophising & & & 2.45 & 1.43 & 0.93 & 0.80 & 1.08 & .351 \\
\hline \multicolumn{9}{|l|}{ Treatment beliefs } \\
\hline Expectancy & - & - & 0.08 & 2.79 & $1.11^{*}$ & 1.02 & 1.21 & .014 \\
\hline Holistic health & - & - & 30.38 & 5.54 & 0.99 & 0.96 & 1.03 & .785 \\
\hline Natural treatments & - & - & 31.86 & 6.60 & 1.00 & 0.97 & 1.03 & .988 \\
\hline Participation in treatment & - & - & 26.85 & 4.88 & $1.05^{*}$ & 1.01 & 1.10 & .030 \\
\hline \multicolumn{9}{|l|}{ Appraisals } \\
\hline Credibility of acupuncture & - & - & 0.11 & 2.64 & $1.08^{*}$ & 1.00 & 1.17 & .046 \\
\hline Acupuncturist & - & - & 60.31 & 8.86 & $1.03^{*}$ & 1.00 & 1.06 & .028 \\
\hline Change in disability & & & & & & & & .112 \\
\hline No change ${ }^{a}$ & 49 & 15.1 & - & - & & & & \\
\hline Small deterioration & 78 & 24.1 & - & - & 1.28 & 0.63 & 2.62 & .500 \\
\hline Moderate deterioration & 16 & 4.9 & - & - & 2.29 & 0.69 & 7.58 & .174 \\
\hline Small improvement & 108 & 33.3 & - & - & 0.74 & 0.38 & 1.47 & .393 \\
\hline Moderate improvement & 73 & 22.5 & - & - & 1.41 & 0.68 & 2.92 & .353 \\
\hline Change in pain & & & & & & & & .777 \\
\hline No change ${ }^{a}$ & 74 & 22.8 & - & - & & & & \\
\hline Small deterioration & 50 & 15.4 & - & - & 0.92 & 0.45 & 1.89 & .827 \\
\hline Moderate deterioration & 31 & 9.6 & - & - & 1.07 & 0.46 & 2.47 & .880 \\
\hline Small improvement & 75 & 23.1 & - & - & 1.34 & 0.70 & 2.56 & .370 \\
\hline Moderate improvement & 94 & 29.0 & - & - & 0.92 & 0.50 & 1.69 & .784 \\
\hline \multicolumn{9}{|l|}{ Change in Wellbeing } \\
\hline No change ${ }^{a}$ & 67 & 20.7 & - & - & & & & .637 \\
\hline Small deterioration & 64 & 19.8 & - & - & 1.50 & 0.75 & 2.99 & .250 \\
\hline Moderate deterioration & 69 & 21.3 & - & - & 1.00 & 0.51 & 1.97 & .994 \\
\hline
\end{tabular}


Table 3 Descriptive statistics and univariable logistic regression analyses of adherence on psychological variables $(n=324)$ (Continued)

\begin{tabular}{|c|c|c|c|c|c|c|c|c|}
\hline Small improvement & 62 & 19.1 & - & - & 1.33 & 0.66 & 2.66 & .422 \\
\hline Moderate improvement & 62 & 19.1 & - & - & 0.96 & 0.48 & 1.92 & .911 \\
\hline Value for money & 92 & 28.4 & - & - & 1.55 & 0.95 & 2.52 & .079 \\
\hline Not difficult to travel & 184 & 56.8 & - & - & 1.12 & 0.72 & 1.74 & .607 \\
\hline Convenient appointments & 106 & 32.7 & - & - & $1.67^{*}$ & 1.04 & 2.67 & .033 \\
\hline Not effortful to attend & 219 & 67.6 & - & - & $2.29^{* *}$ & 1.42 & 3.70 & .001 \\
\hline Not too expensive & 118 & 36.4 & - & - & $1.90^{* *}$ & 1.20 & 3.01 & .006 \\
\hline
\end{tabular}

Notes. ${ }^{*} p<.05 .{ }^{* *} p<.01 .{ }^{\mathrm{a}}$ Reference category

Table 4 Multiple logistic regression analysis of predictors of attendance $(n=324)$

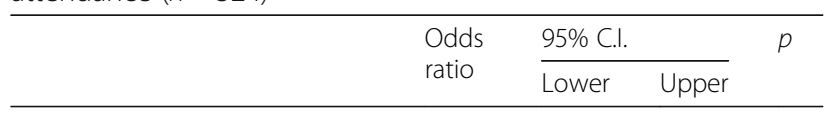

Demographic/Clinical characteristics

\begin{tabular}{|c|c|c|c|c|}
\hline \multicolumn{5}{|l|}{ Gender } \\
\hline Female & 1.40 & 0.81 & 2.41 & .223 \\
\hline Age & 1.01 & 0.99 & 1.03 & .240 \\
\hline Prior acupuncture & 1.55 & 0.93 & 2.59 & .094 \\
\hline Co-treatment & 1.46 & 0.78 & 2.76 & .240 \\
\hline \multicolumn{5}{|l|}{ Sector } \\
\hline Private & 0.33 & 0.09 & 1.19 & .089 \\
\hline \multicolumn{5}{|l|}{ Clinic type } \\
\hline CAM or acupuncture/TCM ${ }^{a}$ & & & & .820 \\
\hline Physiotherapy & 0.93 & 0.24 & 3.64 & .921 \\
\hline Pain clinic & 0.74 & 0.16 & 3.56 & .710 \\
\hline GP & 0.63 & 0.13 & 3.11 & .566 \\
\hline \multicolumn{5}{|l|}{ Acupuncture style } \\
\hline \multicolumn{5}{|l|}{ Unclear ${ }^{a}$} \\
\hline Western & 0.79 & 0.39 & 1.61 & .520 \\
\hline Traditional or TCM & 0.69 & 0.31 & 1.55 & .368 \\
\hline Mixed & 1.32 & 0.37 & 4.79 & .671 \\
\hline \multicolumn{5}{|l|}{ Sychological variables } \\
\hline \multicolumn{5}{|l|}{ Illness perceptions } \\
\hline Treatment control & 0.99 & 0.83 & 1.17 & .869 \\
\hline Identity & $0.81^{* *}$ & 0.90 & 0.94 & .006 \\
\hline Comprehensible & 1.04 & 0.93 & 1.15 & .521 \\
\hline \multicolumn{5}{|l|}{ Treatment beliefs } \\
\hline Expectancy & 1.10 & 0.94 & 1.28 & .259 \\
\hline Participation in treatment & 1.05 & 1.00 & 1.11 & .072 \\
\hline \multicolumn{5}{|l|}{ Appraisals } \\
\hline Credibility of acupuncture & 0.96 & 0.81 & 1.14 & .663 \\
\hline Acupuncturist & 1.00 & 0.97 & 1.03 & .850 \\
\hline Convenient appointments & 1.40 & 0.79 & 2.45 & .254 \\
\hline Not effortful to attend & $2.09^{*}$ & 1.18 & 3.73 & .012 \\
\hline Not too expensive & 1.23 & 0.72 & 2.08 & .454 \\
\hline
\end{tabular}

Notes. ${ }^{*} p<.05 .{ }^{* *} p<.01 .{ }^{a}$ Reference category motivation for acupuncture. Acupuncture users in the NHS might be more likely than those in the private sector to adhere to appointments because they are grateful for free access to acupuncture [13] and/or because they are more likely to have shorter treatment courses of fixed duration [59]. Physiotherapy, GP and pain clinics are more likely to be in the NHS than are CAM clinics, which might explain increased adherence in the former settings. The impact of age was small - for each additional year of age the odds of attending all appointments were 1.02 times higher - and may indicate increasing commitment to health in general with increasing age. A recent large-scale study of adherence to medications in chronic illness found that older adults were also more likely to adhere to medications [65].

Odds of attending all acupuncture appointments increased with: weak perceptions that LBP causes many severe symptoms; high expectations of effectiveness and strong preferences for participating in treatment; and positive appraisals of the acupuncturist, appraisals of acupuncture as credible, and appraisals of acupuncture appointments as convenient, affordable, and not effortful to attend. Patients who do not associate lots of severe symptoms with their LBP might be more able physically to attend acupuncture appointments, which would lead to increased adherence (although LBP severity was not associated with adherence). Alternatively, patients who associate lots of severe symptoms with their LBP might feel they need a comprehensive multidisciplinary treatment to address these symptoms. While traditional acupuncture typically addresses the patient as a whole rather than focusing on a single symptom or condition, non-traditional acupuncture (e.g. Western styles) may be more symptom-focussed [66] and only approximately $25 \%$ of patients in this study were receiving traditional acupuncture. It is worth noting however that acupuncture style did not in itself predict adherence in this study.

People who expected acupuncture to be effective and believed it is important to participate in treatment were more likely to attend all their appointments, which can be understood as demonstrating the tendency towards common-sense coherence between treatment beliefs and 
Table 5 Partial correlations between appraisals, illness perceptions and treatment beliefs

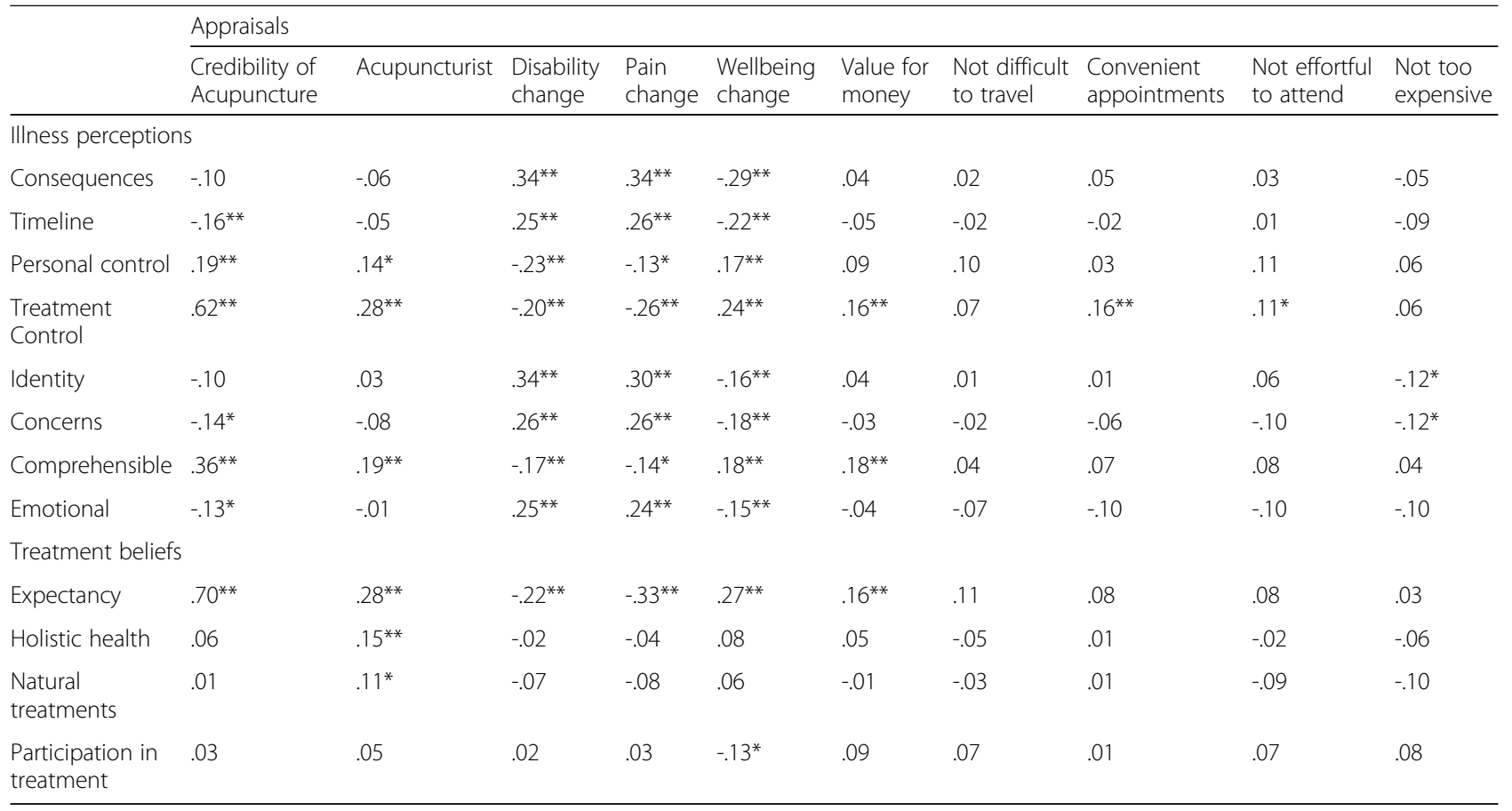

Notes. Each partial correlation controls for the baseline score on the relevant illness perception/treatment belief. ${ }^{*} p<.05 .{ }^{* *} p<.01$

adherence suggested by the extended common-sense model [34-36]. That participants apparently appraised multiple aspects of treatment when deciding whether to continue attending appointments is consistent with qualitative research in which patients evaluated multiple aspects of CAM when deciding whether to continue treatment [21]. This finding also supports the explication of multiple dimensions of appraisal in the dynamic extended common sense model for CAM [28]. Experiencing early changes in symptoms did not predict attendance, which can be explained if participants, like other CAM users [21], preferred to delay judging the effectiveness of therapy or if acupuncturists, like chiropractors [42] and rehabilitation therapists [67], reassured patients and helped them to interpret early changes (or lack thereof) positively.

In the final logistic regression model, a combination of demographic, clinical and psychological variables accounted for $20 \%$ of the variance in complete attendance. Psychological and other variables contributed similar amounts, confirming that attendance is dependent on multiple factors of different types. However, only two variables emerged as significant predictors of attendance (perceiving that one's LBP causes many severe symptoms and perceiving acupuncture appointments as not too much effort to attend) which suggests shared variance among the predictors and possible mediation effects. A large proportion of variance in attendance $(80 \%)$ remained unaccounted for by our predictors. This is broadly comparable to our previous study of adherence to diverse CAM therapies in which illness perceptions, treatment beliefs and treatment appraisals explained $25 \%$ of the variance in attendance, $19 \%$ of the variance in adherence to lifestyle recommendations and $39 \%$ of the variance in adherence to remedies [28]. These findings strongly suggest that additional variables to the illness perceptions, treatment beliefs, and treatment appraisals measured in this study are needed to understand and predict complete attendance for acupuncture and other CAM treatments. Such variables might include not only other beliefs, such as perceived need for and concerns about treatment $[46,68]$, health locus of control (previously associated with acupuncture use [69]), and health-related selfperceptions (previously predicted CAM use [70]), but also social constructs such as social network characteristics (associated with CAM use [71]) and social support (associated with adherence to biomedical therapies [72]). Alternative measures of some constructs might have been more appropriate. For example, self-rated health changes may be more strongly related to adherence than researcher-computed health changes; other measures related to the therapeutic relationship such as working alliance [73] might better capture the impact of therapist-patient communication on adherence [42].

Strengths of this study include its prospective design, use of reliable and previously validated measures of multiple predictors of adherence derived from an established 
theoretical framework, and the comparatively large sample of acupuncture patients drawn from diverse clinics across the UK. The lack of an objective measure of attendance is a limitation, although the possible bias introduced by self-report measures of adherence is somewhat mitigated by the combined use of patient and practitioner reports. It is possible that acupuncture patients who volunteer to participate in research are more likely to adhere to treatment than patients who do not volunteer, and if this were the case then this study may have overestimated adherence rates. We could locate no comparable published data on adherence in practice to test this possibility.

The results suggest several ways in which acupuncturists could encourage patients to attend all recommended appointments and thus probably improve patient outcomes. Patients who associated lots of severe symptoms with their LBP were less likely to adhere, so acupuncturists from all traditions could ensure they discuss and address diverse symptoms and comorbidities with patients. Patients who appraised their acupuncturist positively - finding them to be trustworthy and good communicators - were more likely to attend than other patients. This is consistent with previous studies in CAM [28] and biomedicine [74], and reinforces the importance of good communication and relationship-building skills for encouraging adherence to treatment recommendations. Acupuncturists may also be able to structure their services to facilitate adherence and minimise the practical barriers that were associated with incomplete attendance in this study. This would entail offering more convenient and affordable appointments that patients can easily fit into their lives and attend with minimal effort. Acupuncturists could consider asking patients to complete the five practical items from the TAQ [28] early in treatment to identify patients most at risk of early discontinuation and open up a discussion with them about ways to ease the burden of attending appointments.

\section{Conclusions}

In conclusion, the results broadly supported the dynamic extended CSM for CAM use. Adherence to acupuncture was predicted by patients' perceptions of their LBP, their expectations of acupuncture, and their appraisals of their early experiences of their acupuncturist, the credibility of acupuncture, and the practicalities of attending appointments. Contrary to predictions, experiencing early changes in symptoms did not predict attendance. We have suggested several ways in which acupuncturists could encourage patients to attend all recommended appointments. Future research should explore additional variables to improve our understanding of adherence to acupuncture.

\section{Acknowledgements}

We are grateful to the Primary Care Research Network, the Acupuncture Association of Chartered Physiotherapists, and British Acupuncture Council, and the British Medical Acupuncture Society for help recruiting acupuncturists. We are grateful to the acupuncturists for recruiting our participants and to the participants for completing the questionnaires. We thank Jane Cousins, Naomi Guppy and Gemma Fitzsimmons for administrative support.

\section{Funding}

This study was funded by Arthritis Research UK (Career Development Fellowship 18099 to FLB). GTL's post is supported by a grant from the Rufford Maurice Laing Foundation. The funding bodies had no role in the design, collection, analysis and interpretation of the data, or in the writing of the manuscript or in the decision to submit the manuscript for publication.

Availability of data and materials

Data will not be available on a public repository because participants were not asked to consent for this.

\section{Authors' contributions}

FLB conceived of the study, led its design, data acquisition, analysis and interpretation, and drafted the manuscript for publication. GTL, LY, PL and CC contributed to study conception and design and revised the article critically for important intellectual content. All authors have given final approval of the version to be published.

\section{Competing interests}

The authors declare that they have no competing interests.

Consent for publication

Not applicable.

\section{Ethics approval and consent to participate}

This study was approved by Southampton and South West Hampshire Research Ethics Committee (A) (08/H0502/92). All participants gave written informed consent.

\section{Author details}

${ }^{1}$ Psychology, Faculty of Social and Human Sciences, University of Southampton, Building 44 Highfield Campus, Southampton SO17 1BJ, UK. ${ }^{2}$ MRC Lifecourse Epidemiology Unit, University of Southampton,

Southampton General Hospital, Tremona Road, Southampton SO16 6YD, UK. ${ }^{3}$ Primary Care and Population Sciences, Aldermoor Health Centre, University of Southampton, Southampton SO16 5ST, UK.

Received: 2 April 2016 Accepted: 6 December 2016

Published online: 03 January 2017

\section{References}

1. Chou R, Qaseem A, Snow V, Casey D, Cross Jr JT, Shekelle P, Owens DK, for the Clinical Efficacy Assessment Subcommittee of the American College of $P$, the American College of Physicians/American Pain Society Low Back Pain Guidelines P. Diagnosis and treatment of low back pain: a joint clinical practice guideline from the American College of Physicians and the American Pain Society. Ann Intern Med. 2007;147(7):478-91.

2. Savigny P, Kuntze S, Watson P, Underwood M, Ritchie G, Cotterell M, Hill D, Browne N, Buchanan E, Coffey P, et al. Low back pain. Early management of persistent non-specific low back pain. In: NICE clinical guideline 88. London: National Collaborating Centre for Primary Care and Royal College of General Practitioners; 2009. www.nice.org.uk/CG88.

3. Guy R, Hocking J, Wand H, Stott S, Ali H, Kaldor J. How effective are short message service reminders at increasing clinic attendance? A meta-analysis and systematic review. Health Serv Res. 2012;47(2):614-32.

4. Hasvold PE, Wootton R. Use of telephone and SMS reminders to improve attendance at hospital appointments: a systematic review. J Telemed Telecare. 2011;17(7):358-64.

5. Hopton AK, Curnoe S, Kanaan M, MacPherson H. Acupuncture in practice: mapping the providers, the patients and the settings in a national crosssectional survey. BMJ Open. 2012; 2(1): e000456. doi:10.1136/bmjopen-2011000456.

6. Murthy V, Sibbritt DW, Adams J. An integrative review of complementary and alternative medicine use for back pain: a focus on prevalence, reasons 
for use, influential factors, self-perceived effectiveness, and communication. Spine J. 2015;15(8):1870-83.

7. Horne R. Compliance, adherence, and concordance*. Chest. 2006;130(1 suppl):65S-72S.

8. Granger BB, Swedberg K, Ekman I, Granger CB, Olofsson B, McMurray JJV, Yusuf S, Michelson EL, Pfeffer MA. Adherence to candesartan and placebo and outcomes in chronic heart failure in the CHARM programme: doubleblind, randomised, controlled clinical trial. Lancet. 2005;366(9502):2005-11.

9. Moroz A, Spivack S, Lee MHM. Adherence to acupuncture treatment for chronic pain. J Altern Complement Med. 2004;10(5):739-40.

10. Cherkin DC, Eisenberg D, Sherman KJ, Barlow W, Kaptchuk TJ, Street J, Deyo RA. Randomized trial comparing traditional chinese medical acupuncture, therapeutic massage, and self-care education for chronic low back pain. Arch Intern Med. 2001;161(8):1081-8.

11. Haake M, Muller HH, Schade-Brittinger C, Basler HD, Schafer H, Maier C, Endres HG, Trampisch HJ, Molsberger A. German acupuncture trials (GERAC) for chronic low back pain. Randomized, multicenter, blinded, parallel-group trial with 3 groups. Arch Intern Med. 2007;167(17):1892-8.

12. Witt CM, Jena S, Selim D, Brinkhaus B, Reinhold T, Wruck K, Liecker B, Linde K Wegscheider K, Willich SN. Pragmatic randomized trial evaluating the clinical and economic effectiveness of acupuncture for chronic low back pain Am J Epidemiol. 2006;164(5):487-96.

13. Bishop FL, Barlow F, Coghlan B, Lee P, Lewith GT. Patients as healthcare consumers in the public and private sectors: a qualitative study of acupuncture in the UK. BMC Health Serv Res. 2011;11(129). doi:10.1186/1472-6963-11-129. https://bmchealthservres.biomedcentral.com/articles/10.1186/1472-6963-11-129.

14. Cassidy CM. Chinese medicine users in the United States - Part II: preferred aspects of care. J Altern Complement Med. 1998;4(2):189-202.

15. Gould A, MacPherson H. Patient perspectives on outcomes after treatment with acupuncture. J Altern Complement Med. 2001;7(3):261-8.

16. Hughes JG. "When I first started going I was going in on my knees, but I came out and I was skipping": Exploring rheumatoid arthritis patients' perceptions of receiving treatment with acupuncture. Complement Ther Med. 2009;17(5):269-73.

17. Paterson C, Britten N. Acupuncture as a complex intervention: a holistic model. J Altern Complement Med. 2004;10(5):791-801.

18. Rugg S, Paterson C, Britten N, Bridges J, Griffiths P. Traditional acupuncture for people with medically unexplained symptoms: a longitudinal qualitative study of patients' experiences. Br J Gen Pract. 2011;61:e306-15.

19. Frank R, Stollberg G. Medical acupuncture in Germany: patterns of consumerism among physicians and patients. Sociol Health IIIn. 2004;26:351-72.

20. Cheshire A, Polley M, Peters D, Ridge D. Is it feasible and effective to provide osteopathy and acupuncture for patients with musculoskeletal problems in a GP setting? A service evaluation. BMC Fam Pract. 2011; 12(1):49.

21. Bishop FL, Yardley L, Lewith GT. Why consumers maintain complementary and alternative medicine use: a qualitative study. J Altern Complement Med. 2010;16(2):175-82.

22. Cartwright T, Torr R. Making sense of illness: the experiences of users of complementary medicine. J Health Psychol. 2005;10(4):559-72.

23. Caspi O, Koithan M, Criddle MW. Alternative medicine or "alternative" patients: a qualitative study of patient-oriented decision-making processes with respect to complementary and alternative medicine. Med Decis Making. 2004;24(1):64-79.

24. Mercer SW, Reilly D. A qualitative study of patient's views on the consultation at the Glasgow Homoeopathic Hospital, an NHS integrative complementary and orthodox medical care unit. Patient Educ Couns. 2004;53(1):13-8

25. Thorne S, Paterson B, Russell C, Schultz A. Complementary/alternative medicine in chronic illness as informed self-care decision making. Int I Nurs Stud. 2002;39(7):671-83.

26. Sirois FM, Gick ML. An investigation of the health beliefs and motivations of complementary medicine clients. Soc Sci Med. 2002;55(6):1025-37.

27. Furnham A. Are modern health worries, personality and attitudes to science associated with the use of complementary and alternative medicine? Br J Health Psychol. 2007;12:229-43.

28. Bishop FL, Yardley L, Lewith GT. Treatment appraisals and beliefs predict adherence to complementary therapies: a prospective study using a dynamic extended self-regulation model. Br J Health Psychol. 2008;13(4):701-18.

29. Endrizzi C, Rossi E. Patient compliance with homeopathic therapy. Homeopathy. 2006;95:206-14.
30. Rao JK, Kroenke K, Mihaliak KA, Grambow SC, Weinberger M. Rheumatology patients' use of complementary therapies: results from a one-year longitudinal study. Arthritis Care Res. 2003;49(5):619-25.

31. Owens JE, Taylor AG, Degood D. Complementary and alternative medicine and psychologic factors: toward an individual differences model of complementary and alternative medicine use and outcomes. J Altern Complement Med. 1999;5(6):529-41.

32. Sirois FM, Purc-Stephenson RJ. Personality and consultations with complementary and alternative medicine practitioners: a five-factor model investigation of the degree of use and motives. J Altern Complement Med. 2008;14(9):1151-8.

33. Jerant A, Chapman B, Duberstein P, Robbins J, Franks P. Personality and medication non-adherence among older adults enrolled in a six-year trial. Br J Health Psychol. 2011;16(1):151-69.

34. Horne R, Weinman J. Self-regulation and self-management in asthma: exploring the role of illness perceptions and treatment beliefs in explaining non-adherence to preventer medication. Psychol Health. 2002;17(1):17-32.

35. Horne R. Representations of medication and treatment: advances in theory and measurement. In: Petrie KJ, Weinman JA, editors. Perceptions of Health and IIIness. Amsterdam: Harwood Academic Publishers; 1997. p. 155-88.

36. Leventhal HA, Brissette I, Leventhal EA. The common-sense model of self-regulation of health and illness. In: Cameron LD, Leventhal $H$, editors. The self-regulation of health and illness behaviour. London: Routledge; 2003. p. 42-65.

37. Olchowska-Kotala A. IIIness representations in individuals with rheumatoid arthritis and the willingness to undergo acupuncture treatment. Eur J Integr Med. 2013;5(4):347-51.

38. Bishop FL, Yardley L, Lewith GT. Why do people use different forms of complementary medicine? Multivariate associations between treatment and illness beliefs and complementary medicine use. Psychol Health. 2006;21:683-98.

39. Porter MC, Diefenbach MA. Pushed and pulled: the role of affect and cognition in shaping CAM attitudes and behavior among men treated for prostate cancer. J Health Psychol. 2009;14(2):288-96.

40. Pound P, Britten N, Morgan M, Yardley L, Pope C, Daker-White G, Campbell R. Resisting medicines: a synthesis of qualitative studies of medicine taking. Soc Sci Med. 2005;61:133-55.

41. Vermeire $E$, Hearnshaw $H$, Van Royen $P$, Denekens J. Patient adherence to treatment: three decades of research. A comprehensive review. J Clin Pharm Ther. 2001;26:331-42.

42. Yardley L, Sharples K, Beech S, Lewith G. Developing a dynamic model of treatment perceptions. J Health Psychol. 2001;6(3):269-82.

43. Diefenbach MA, Leventhal $H$. The common-sense model of illness representation: theoretical and practical considerations. J Soc Distress Homeless. 1996;5(1):11-38.

44. Brandes K, Mullan B. Can the common-sense model predict adherence in chronically ill patients? A meta-analysis. Health Psychol Rev. 2014;8(2):129-53.

45. Nicklas LB, Dunbar M, Wild M. Adherence to pharmacological treatment of non-malignant chronic pain: the role of illness perceptions and medication beliefs. Psychol Health. 2009;25(5):601-15.

46. Horne R, Chapman SCE, Parham R, Freemantle N, Forbes A, Cooper V. Understanding patients' adherence-related beliefs about medicines prescribed for long-term conditions: a meta-analytic review of the necessity-concerns framework. PLoS One. 2013;8(12), e80633.

47. Arbuthnott A, Sharpe D. The effect of physician-patient collaboration on patient adherence in non-psychiatric medicine. Patient Educ Couns. 2009; 77(1):60-7.

48. Julius RJ, Novitsky MAJ, Dubin WR. Medication adherence: a review of the literature and implications for clinical practice. J Psychiatr Pract. 2009;15(1):34-44. doi:10.1097/01.pra.0000344917.43780.77.

49. Safran DG, Taira DA, Rogers WH, Kosinski M, Ware JE, Tarlov AR. Linking primary care performance to outcomes of care. J Fam Pract. 1998;47(3):213-20.

50. Bishop FL, Yardley L, Prescott P, Cooper C, Little P, Lewith GT. Psychological covariates of longitudinal changes in back-related disability in patients undergoing acupuncture. Clin J Pain. 2015;31(3):254-64.

51. Broadbent E, Petrie KJ, Main J, Weinman J. The brief illness perception questionnaire. J Psychosom Res. 2006;60:631-7.

52. Waddell G, Newton M, Henderson I, Somerville D, Main C. A fear-avoidance beliefs questionnaire (FABQ) and the role of fear-avoidance beliefs in chronic low back pain and disability. Pain. 1993;52:157-68.

53. Rosentiel AK, Keefe FJ. The use of coping strategies in chronic low back pain patients: relationship to patient characteristics and current adjustment. Pain. 1983;17:33-44. 
54. Bishop FL, Yardley L, Lewith G. Developing a measure of treatment beliefs: the complementary and alternative medicine beliefs inventory. Complement Ther Med. 2005;13:144-9.

55. Devilly GJ, Borkovec TD. Psychometric properties of the credibility/ expectancy questionnaire. J Behav Ther Exp Psychiatry. 2000;31:73-86.

56. Roland M, Morris R. A study of the natural history of back pain. Part I: development of a reliable and sensitive measure of disability in low-back pain. Spine. 1983;8(2):141-4.

57. Dworkin RH, Turk DC, Farrar JT, Haythornthwaite JA, Jensen MP, Katz NP, Kerns RD, Stucki G, Allen RR, Bellamy N. Core outcome measures for chronic pain clinical trials: IMMPACT recommendations. Pain. 2005;113(1-2):9-19.

58. Bell IR, Cunningham V, Caspi O, Meek P, Ferro L. Development and validation of a new global well-being outcomes rating scale for integrative medicine research. BMC Complement Altern Med. 2004;4:1. doi:10.1186/ 1472-6882-1184-1181.

59. Bishop FL, Amos N, Yu H, Lewith GT. Health-care sector and complementary medicine: practitioners' experiences of delivering acupuncture in the public and private sectors. Prim Health Care Res Dev. 2012;13(03):269-78.

60. Edwards P, Cooper R, Roberts I, Frost C. Meta-analysis of randomised trials of monetary incentives and response to mailed questionnaires. J Epidemiol Community Health. 2005;59:987-99.

61. Edwards P, Roberts I, Clarke M, DiGuiseppi C, Pratap S, Wentz R, Kwan I. Increasing response rates to postal questionnaires: systematic review. Br Med J. 2002;324:1183-93.

62. Tabachnick BG, Fidell LS. Using multivariate statistics, vol. 4. Boston: Allyn and Bacon; 2001.

63. Box GEP, Tidwell PW. Transformation of the independent variables. Technometrics. 1962:4(4):531-50.

64. Field A. Discovering statistics using SPSS for windows. London: Sage; 2000

65. Rolnick SJ, Pawloski PA, Hedblom BD, Asche SE, Bruzek RJ. Patient characteristics associated with medication adherence. Clin Med Res. 2013; 11(2):54-65. doi:10.3121/cmr.2013.1113.

66. White A, the editorial board of Acupuncture in M. Western medical acupuncture: a definition. Acupunct Med. 2009;27(1):33-5.

67. Muller I, Kirby S, Yardley L. The therapeutic relationship in telephonedelivered support for people undertaking rehabilitation: a mixed-methods interaction analysis. Disabil Rehabil. 2015:37(12):1060-5.

68. Hök J, Falkenberg T, Tishelman C. Lay perspectives on the use of biologically based therapies in the context of cancer: a qualitative study from Sweden. J Clin Pharm Ther. 2011;36(3):367-75.

69. Cramer H, Chung VCH, Lauche R, Zhang Y, Zhang A, Langhorst J, Dobos G. Characteristics of acupuncture users among internal medicine patients in Germany. Complement Ther Med. 2015;23(3):423-9.

70. Sirois FM. Health-related self-perceptions over time and provider-based Complementary and Alternative Medicine (CAM) use in people with inflammatory bowel disease or arthritis. Complement Ther Med. 2014;22(4):701-9.

71. Goldman AW, Cornwell B. Social network bridging potential and the use of complementary and alternative medicine in later life. Soc Sci Med. 2015:140:69-80.

72. DiMatteo MR. Social support and patient adherence to medical treatment: a meta-analysis. Health Psychol. 2004;23(2):207-18.

73. Fuertes JN, Mislowack A, Bennett J, Paul L, Gilbert TC, Fontan G, Boylan LS The physician-patient working alliance. Patient Educ Couns. 2007;66(1):29-36.

74. Zolnierek KB, DiMatteo MR. Physician communication and patient adherence to treatment: a meta-analysis. Med Care. 2009;47(8):826-34 doi:10.1097/MLR.0b013e31819a5acc.

75. Maughan EF, Lewis JS. Outcome measures in chronic low back pain. Eur Spine J. 2010;19(9):1484-94.

76. Dworkin RH, Turk DC, Wyrwich KW, Beaton D, Cleeland CS, Farrar JT, Haythornthwaite JA, Jensen MP, Kerns RD, Ader DN, et al. Interpreting the clinical importance of treatment outcomes in chronic pain clinical trials: IMMPACT recommendations. J Pain. 2008;9(2):105-21.

\section{Submit your next manuscript to BioMed Central and we will help you at every step:}

- We accept pre-submission inquiries

- Our selector tool helps you to find the most relevant journal

- We provide round the clock customer support

- Convenient online submission

- Thorough peer review

- Inclusion in PubMed and all major indexing services

- Maximum visibility for your research

Submit your manuscript at www.biomedcentral.com/submit
) Biomed Central 